\title{
Snail upregulates FN and LEF transcription negatively feed backed by PPAR-gamma: a general model established for Snail to transactivate mesenchymal genes
}

\author{
Tam Minh Ly \\ Institute of Medical Sciences, Tzu Chi University \\ Yen-Cheng Chen \\ Department of Surgegy, Buddhist Tzu Chi General Hospital \\ Ming-Che Lee \\ Department of Surgery, Buddhist Tzu Chi General Hospital
}

\section{Chuan Chu Chen}

Department of Laboratory Medicine and Biotechnology, Tzu Chi University

\section{Hsin-Hou Chang}

Department of Molecular Biology and Human Genetics, Tzu Chi University

\section{Ren-In You}

Department of Laboratory Medicine and Biotechnology, Tzu Chi University

wen-shengwu ( $\nabla$ wuws@gms.tcu.edu.tw)

Hualien Tzu Chi Hospital

\section{Research}

Keywords: Snail, fibronectin, lymphoid enhancer-binding factor, peroxisome proliferator-activated receptor $-\gamma$, transcription

Posted Date: January 18th, 2021

DOI: https://doi.org/10.21203/rs.3.rs-141261/v1

License: (c) (1) This work is licensed under a Creative Commons Attribution 4.0 International License. Read Full License 


\section{Abstract}

Background Snail (SNA) is responsible for epithelial mesenchymal transition, migration and metastasis of hepatocellular carcinoma. SNA represses the transcription of the essential epithelial marker such as Ecadherin and enhances mesenchymal markers including fibronectin and lymphoid enhancer-binding factor. Our previous studies indicated that SNA, in collaboration with EGR1 and SP1, may directly activate transcription of the mesenchymal markers, matrix degradation enzyme matrix metalloproteinases (MMP9) and zinc finger E-box binding homeobox 1 (ZEB1) in HepG2 cell stimulated by the phorbol ester tumor promoter 12-0-tetradecanoyl-phorbol 13-acetate (TPA). Besides, we pinpointed a SNA binding motif (TCACA) upstream of EGR1/SP1 overlapping region on promoters. In this study, we investigated whether LEF and FN are transcriptionally regulated by SNA in a similar fashion. Moreover, a general model for SNA-upregulated mesenchymal markers is proposed.

Methods RT/PCR and Western blot were used for analyzing gene expression and shRNA technology for depleting SNA. Dual luciferase assay was used for promoter activation; deletion mapping and mutagenesis were used for confirming the indicated promoter region required for transcription activation. ChIP and EMSA were used for validating the binding of the indicated transcription factor on their putative motifs.

Results SNA binding motif and E/S overlapping region are required for TPA-induced transcription of LEF and FN. These were supported by TPA-induced binding of SNA and EGR-1/SP-1 on indicated promoter regions. Moreover, a peroxisome proliferator-activated receptor $y$ motif upstream of SNA binding motif was found to be a negatively regulatory region in TPA-induced promoter activation of FN, LEF, MMP9 and ZEB1. This was supported by that co-treatment of a PPAR-g inhibitor, GW9662, and mutation of PPAR-g binding motif enhanced TPA-induced promoter activity and expression of the aforementioned genes whereas overexpression of PPAR-g reversed it. Moreover, comprehensive screening of the SNAupregulated mesenchymal genes revealed similar sequence architecture on the promoter regions of the candidate genes: SNA binding motif (TCACA) coupled with a downstream EGR/SP1 overlapping region and an upstream PPAR-g binding motif. Among them COX2 and COL1A1 were found to potentially exhibit the same transcription mechanisms described above.

Conclusions We established a general model for SNA-upregulated mesenchymal gene expressions negatively feed backed by PPAR-g.

\section{Background}

The poor prognosis of hepatocellular carcinoma (HCC) is due to frequent metastasis occurring via complicated processes, including epithelial mesenchymal transition (EMT), migration and invasion of primary tumor [1]. Among the metastatic transcription factors, Snail (SNA) was not only overexpressed in $\mathrm{HCC}$ and associated with poor prognosis of $\mathrm{HCC}[2,3]$ but also may accelerate EMT, invasion and metastasis of $\mathrm{HCC}[1,3-6]$. Moreover, SNA was regarded as a promising therapeutic target for preventing 
progression of various tumors including HCC [7]. SNA can be regulated by signalings triggered by a lot of metastatic factors including receptor tyrosine kinase (RTK) and TGF-b. While SNA directly represses epithelial markers like E-cadherin, it also upregulates the mesenchymal markers, including vimentin, fibronectin and matrix metalloproteinases (MMP9) [8-10]. SNA also upregulates other mesenchymal transcriptional factors such as Twist and zinc finger E-box binding homeobox $1[11,12]$ (ZEB1) to complete its EMT program.

The transcriptional mechanisms for SNA to suppress epithelial markers such as E-cadherin are well elucidated. SNA can bind to the E-boxes (5'-CACCTG) on E-cadherin promoter and recruit various epigenetic machineries such as histone deacetylase leading to the repression of E-cadherin expression $[13,14]$. In contrast, the detailed mechanisms for SNA to upregulate transcription of mesenchymal markers are far less clarified. Previous studies indicated that SNA activated transcription of MMP9 and ZEB1 indirectly via regulation of other transcriptional factors such as Twist, Ets-1 and Proximal specificity protein 1 (SP1) or microRNAs in different contexts $[15,16]$. However, our recent report demonstrated that SNA, in collaboration with Early Growth Response 1 (EGR1) and SP1, also directly upregulated transcription of MMP9 and ZEB1 by binding to a specific putative SNA binding motif "TCACA" for activating their promoter [17]. This is in similar with those observed in the transcription of cyclindependent kinase 4/6 (CDK4/6), p15 INK4b a cell cycle related gene upregulated by SNA [18]. Intriguingly, after examining sequences of the other known SNA upregulated mesenchymal markers including vimentin, Twist1, vitronectin, a2 smooth muscle actin (ACTA2), fibronectin (FN) and lymphoid enhancerbinding factor (LEF), we found the similar sequence architecture, ie, the SNA motif TCACA coupled with neighboring EGR1 and SP1 region, also existing in their promoters around 300-2000 bp upstream of the translational initiation sites. Thus it is tempting to investigate whether SNA can directly activate transcriptional upregulation of other EMT-related genes involved in HCC progression such as FN [19] and and LEF [20] in a similar fashion as observed in MMP9 and ZEB1.

By gene expression and promoter analysis coupled with protein DNA interaction assay, we did find that both LEF and FN are transcriptionally regulated by SNA via binding to the proposed SNA binding motifs which is close to EGR1 /SP1 overlapping region. Moreover, we found PPAR-g, a well-known antagonist of SNA, plays as a negative feedback regulator in this process. In addition, cyclooxygenase-2 (COX2), collagen type I alpha 1 chain (COL1A1) and other mesenchymal genes are also potentially regulated in the same way.

\section{Materials And Methods}

\section{Cell culture, chemical and antibody}

The cultured conditions for HCC340 and HepG2 cells were the same as described in our previous report [17]. HCC340 derived from a patient-derived hepatocellular carcinoma cell line from Buddhist Tzu Chi Hospital, Taiwan [21]. Tetradecanoyl phorbol acetate (TPA) and GW9662 were purchased from SigmaAldrich (Poole, UK). Monoclonal Snail (C15D3) and PPAR-g (81B8) antibodies were from Cell Signaling 
(Beverly, MA). The antibodies against EGR1, SP1, MMP9, ZEB1, LEF1, Fibronectin, Histone H3 and GAPDH were purchased from Santa Cruz Biotechnology (California, USA). The snail expression plasmid, p-Snail, driven by CMV promoter within the p-cDNA3 vector, is a gift from Dr. Cheng K.K. in Tzu Chi university. The PPAR-g expression plasmid, p-PPAR-g, driven by CMV promoter within the $\mathrm{p}-\mathrm{cDNA3}$ vector, was purchased from ORIGENE (Rockville, USA).

\section{Constructions of various promoter plasmids for deletion mapping}

The promoter regions in the full-length promoter plasmids of FN, LEF and the other candidate SNA upregulated genes were amplified from genomic sequence of each gene. The PCR products were ligated into pGL3 vector (Promega, Madison, WI, USA). The promoter plasmids of deletion constructs were derived from each full-length promoter by double digestion with various restriction enzymes followed by filling in the restriction site overhangs by Klenow enzyme. Subsequently, the digested DNA fragments will be ligated into pGL3 vector.

\section{Site-directed mutagenesis on promoters}

The full-length promoter plasmids of LEF, FN and the other Snail upregulated genes were used as templates for site-directed mutagenesis using a GeneEditor in vitro site-directed mutagenesis system (Promega, Madison, WI, USA) to obtain various mutant promoters according to the manufacturer's protocol. The bases changed in the site-directed mutagenesis for proposed Snail binding motif (TCACA), the EGR1/SP1 overlapping and PPAR-g binding region were the same as those described in our previous report [18].

Dual luciferase promoter assay was performed as described in our previous report [18].

Chromatin immunoprecipitation (ChIP) assay was performed as described in our previous report [18]; schematic map as supplemental Fig. 6 showed the PCR fragments (Table 2) amplified for the ChIP assay of SNA, EGR1/SP1 overlapping and PPAR-y.

RT-PCR and Quantitative RT-PCR will be performed as described in our previous report [18] and primers used for RT-PCR and real time PCR in gene expression in Table 3

Electrophoresis mobility shift assay (EMSA) was performed as described in our previous report [18]. Nuclear-cytoplasmic protein fractions were collected using the NE-PER Nuclear and Cytoplasmic Extraction Reagents kit (Thermo Fisher Scientific) according to the manufacturer's protocol. The sequence of the biotin-labeled probe ( $25 \mathrm{bp}$ ) and un-labeled competitors of FN promoter (20 bp) are 5'CCCCTTCGCT TCACACAAGTCCAGC3' and 5'CCTTCGCTTCACACAAGTCC3' (wild type)/

5'CCTTCGCTTTGTACAAGTCC3' (mutant), respectively. Also, The sequence of the biotin-labeled probe (25 bp) and un-labeled competitors of LEF promoter (20 bp) are 5'CACACCACACTCACACACCCCAAAA3' and 5'CACCACACTCACACACCCCA3' (wild type)/ 5'CACCACACTTGTACACCCCA3' (mutant).

Western blot was performed as described in our previous reports $[17,18]$. 
shRNA technology was performed as described in our previous reports [18]. The sequence of shRNA fragments targeting different regions of Snail will be the same as those used in our previous study [18].

\section{Statistical analysis}

Data will be analyzed using Student's t-test in Excel. All the quantitative studies will be performed at least in triplicate, as appropriate. Statistical significance between groups will be indicated by ${ }^{*} \mathrm{P}<0.05$ and $\star * P<0.005$.

\section{Results}

\section{Snail is essential for constitutive and TPA-induced gene expression of FN and LEF in HepG2 and HCC340 cells}

Initially, by RT-PCR, we found TPA elevated mRNA of FN and LEF as well as SNA by 2.0 2.7-fold within 1$6 \mathrm{~h}$ in HepG2, one of the conventional HCC cell lines (Fig. 1a). This was also quantitatively confirmed by Q-RT-PCR (supplemental Fig. 1a). Also, Western blot confirmed FN and LEF proteins were elevated by TPA at $6 \mathrm{~h}$ by 1.6-1.8-fold, and declined at $12 \mathrm{~h}$ whereas TPA induced dramatic elevation of SNA earlier at $2 \mathrm{~h}$ and $4 \mathrm{~h}$ and gradually declined at 6 and $12 \mathrm{~h}$ (supplemental Fig. $1 \mathrm{~b}$ ) implicating SNA is an upstream regulator of FN and LEF. In both conventional RT-PCR (supplemental Fig. 1c) and quantitative (Q) RT-PCR (Fig. 1b) analysis, TPA-induced elevation of FN and LEF mRNA were found to be attenuated by three shRNAs of SNA, shSN18, shSN19 and shSN20 by 50-80\% at 4h in HepG2 and HCC340, a patient-derived HCC cell lines used for studying the SNA-upregulated MMP9 and ZEB1 transcription [17]. On the contrary, overexpression of SNA for 6-16 h elevated FN and LEF mRNAs by 3-10-fold in both HepG2 and HCC340 (Fig. 1c and 1d). Collectively, SNA is essential for gene expression of FN and LEF in HCC.

\section{SNA is essential for constitutive and TPA-induced transcriptional activation of FN and LEF in HCC}

We further examined whether TPA can induce promoter activation of FN and LEF in a SNA-dependent manner. To this end, full-length promoter plasmid of FN (FNpro1938) and LEF (LEFpro1897) were constructed by inserting the promoter fragment containing $1938 \mathrm{bp}$ and $1897 \mathrm{bp}$, respectively, upstream of the translation start site of FN and LEF, into PGL3 vector. As shown in Fig. 2a, TPA elevated promoter activity of FNpro1938 (left panel) and LEFpro1897 (right panel) by 20- and 10-fold, respectively, in HepG2. Transfection of SNA shRNAs, including shSN18, shSN19 or shSN20 suppressed the TPA-induced promoter activity of FNpro1938 and LEF pro1897 by 38-60\% compared with that of the control (Luciferase, Luc) shRNA group. Similarly, TPA induced promoter activity of FNpro1938 and LEFpro1891 by 25 and 12-fold, respectively, in HCC340, which can be suppressed by aforementioned SNA shRNA by $60-70 \%$ (Fig. 2b). Moreover, overexpression of SNA increased constitutive promoter activity of FNpro1938 and LEFpro1897 by 2-2.5-fold in HCC340 (Fig. 2c) and HepG2 (data not shown). Collectively, SNA is essential for constitutive and TPA-induced transcriptional activation of FN and LEF in HCC. 


\section{Deletion mapping identified SNA motif coupled with the adjacent EGR1/SP1 overlapping regions within TPA-response element on both FN and LEF promoters}

Further, we sought to identify the TPA-responsive element in promoters of FN and LEF and examined whether it contained the proposed SNA binding region "TCACA" and putative EGR1/SP1 overlapping motif as described previously [17]. According to the Genomatix software, there are three and two proposed SNA binding regions, respectively, locating on promoter of FN (-1187 to -547 bp upstream of the translation start site) and LEF (-1621 to -1211 bp upstream of the translation start site) (supplemental Fig. 3a, b). To examine whether any of these SNA binding motifs were required for promoter activation of both FN and LEF, deletion mapping analysis using 5 ' end truncated mutants including FNpro1150, FNpro750, FNpro700 and FNpro568 (excluding 0, 1, 2 and 3 SNA region, respectively, from 5 ' end on fulllength FN promoter) (Fig. 3a, b upper left panel) and LEFpro1595, LEFpro1300 and LEFpro1231 (excluding 0,1 , and 2 SNA region, respectively, from 5 ' end on full-length LEF promoter) (Fig. 3 a, b lower left panel) were performed. Surprisingly, we found a significantly higher TPA-induced promoter activity of FNpro1150 (deleted with $5^{\prime}$ end region upstream of the $1^{\text {st }}$ SNA motif), compared with full-length FNpro1938 in both HepG2 (Fig. 3a upper right panel) and HCC340 (Fig. 3b upper right panel). Similarly, LEF pro1595 (with small deletion in the $5^{\prime}$ end region upstream of the $1^{\text {st }}$ SNA motif) has significantly higher TPA-induced promoter activity compared with that of full-length LEFpro1897 in both HepG2 (Fig. 3a lower right panel) and HCC340 (Fig. 3b lower right panel). These implicated that a negative regulatory region located upstream of SNA region in full-length promoter of both FN and LEF, as will be described in below section. Further, the TPA-induced promoter activity of FNpro750 and FNpro700, the FN mutants lacking one and two distal SNA motifs, respectively, decreased only 10-30\% compared with FNpro1150. Strikingly, FNpro568, the mutant lacking all 3 SNA regions, exhibited a dramatic reduction (by $68 \%$ ) of TPA-induced promoter activity compared with FNpro1150 in HepG2 (Fig. 3a upper right panel) and HCC340 (Fig. 3b upper right panel). Similarly, the TPA-induced promoter activity of LEFpro1300, the LEF mutants lacking one SNA motif, exhibited minor difference (by 10-20\%) compared with LEF pro1595, whereas LEFpro1231, the mutant lacking both SNA motifs exhibited a greater reduction (by $70-80 \%$ ) of TPA-induced promoter activity than those of LEFpro1595 and LEFpro1300 in HepG2 (Fig. 3a lower right panel) and HCC340 (Fig. 3b lower right panel). Together, these implied that the most proximal (3') SNA motifs are required for TPA-induced promoter activity of both FN and LEF. Interestingly, the TPAresponsive SNA motifs on both promoters are close to a EGR1/SP1 (E/S) overlapping region which was known to be required for TPA-induced, SNA-mediated MMP9 and ZEB1 promoter activation [17]. Thus, it is very probable that the E/S overlapping regions close to the candidate SNA site on both promoters are also involved in SNA-dependent transcriptional upregulation in FN and LEF. Indeed, FNpro330 and LEFpro1100 which lack E/S overlapping and all the SNA regions, showed a further decrease (by $60-80 \%$ ) of TPA-induced promoter activity compared with those of the FNpro568 and LEFpro1231 that still contained E/S (Fig. 3a, b). Collectively, these strongly suggest that the most proximal (3') SNA region coupled with the adjacent E/S overlapping regions are essential for TPA-induced promoter activations of both FN and LEF. 


\section{Mutagenesis on promoter validated SNA binding motif and E/S overlapping region required for transcription of FN and LEF}

To prove whether the candidate SNA binding motifs are required for transcription of LEF and FN, site directed mutagenesis were performed, producing promoter mutants with altered sequence (TCACA $®$ TTGTA) at indicated SNA motifs (PM 1-3). As shown in Fig. 3 (c, d), FN promoter mutant with altered sequence at the proximal ( $3^{\prime}$ ) SNA binding motif (PM3) exhibited a $60 \%$ decrease of TPA-induced promoter activity compared with that of the wild type FNpro1150 in both HepG2 (Fig. 3c, upper panel) and HCC340 (Fig. 3d, upper panel) at $12 \mathrm{~h}$, whereas mutation of FN promoter at the middle SNA (PM2) and the distal (5') SNA region (PM1) didn't decrease the TPA-induced promoter activity. Similarly, LEF promoter mutant with the altered sequence at the proximal ( $\left.3^{\prime}\right)$ SNA (PM2) but not the distal (5') SNA (PM1) exhibited a significantly decrease (by $50-70 \%$ ) of TPA-induced promoter activity compared with that of the wild type LEFpro1595 in both HepG2 (Fig. 3c, lower panel) and HCC340 (Fig. 3d, lower panel). Collectively, these validated that the most proximal ( $\left.3^{\prime}\right)$ SNA binding regions on promoters of both FN and LEF are essential for TPA-induced promoter activation. In addition, mutation (CCCCGCCT ®CCCTATCT) on the E/S region (-1195 to -1179 bp) of LEFpro1595 (LEFpro1595 E/S-PM1) close to the active SNA motif, but not the next (proximal) E/S region (-1134 to -1119 bp) (LEFpro1595 E/S-PM2) also attenuated the TPA-enhanced promoter activity of LEFpro1595 by 33\% in HepG2 (Fig. 3c, lower panel) and HCC340 (Fig. 3d, lower panel). As a negative control, mutagenesis on the FOXA2 region close to the active SNA region has no effect on TPA-induced promoter activity of LEF (Fig. 3c, d, lower panel). Taken together, the proximal (3') SNA region coupled with the adjacent E/S overlapping region are responsible for TPAinduced promoter activation of FN and LEF.

\section{PPAR-g is the negative feedback regulator in SNA-mediated transcription of FN and LEF}

In the deletion mapping analysis, we found a negative regulatory region upstream of the distal $\left(5^{\prime}\right)$ SNA binding motif on promoters of both genes as described above (Fig. 3a, b). Notably, a putative binding motif of peroxisome proliferator-activated receptor Y (PPAR-g) transcriptional factor according to the JASPAR database, was identified within these regions (Fig. 3 and supplemental Fig. 3). Interestingly, both SNA and PPAR-g may antagonize gene expressions of each other. PPAR-g is well known to be a repressor of SNA for blocking EMT [22]. On the other hand, SNA can inhibit the expression of PPAR-g for adipocyte differentiation [23]. In a Q-RT-PCR analysis, PPAR-g mRNA was increased by treatment of TPA at $6 \mathrm{~h}$ by 2.8-fold, further increased to 3.3-fold at $12 \mathrm{~h}$ and declined to 2.0-fold at $14 \mathrm{~h}$ (supplemental Fig. 2a, left panel). As expected, it can be suppressed by GW9662, one of the PPAR-g antagonists, by $50 \%$ at $12 \mathrm{~h}$ time point (supplemental Fig. 2a, left panel). Moreover, TPA-induced PPAR- $\gamma$ mRNA at $12 \mathrm{~h}$ was enhanced by SNA shRNA, shSN18, and on the contrary, it was diminished by overexpression of SNA approximately by $1.5-2$-fold at $12 \mathrm{~h}$ (supplemental Fig. $2 \mathrm{~b}$, right panel). Thus, SNA can be a negative regulator of PPAR- $\gamma$ in TPA-treated HCC. On the other hand, we examined whether PPAR-y plays a negative regulatory role in the expression of SNA and the SNA-upregulated mesenchymal genes. In Q-RT-PCR of SNA, FN and LEF (supplemental Fig. 1a), GW9662 reversed the down regulation of mRNA of SNA, FN and LEF by 50 60\% at $12 \mathrm{~h}$ of TPA treatment. Similarly, in Western blot of SNA (supplemental Fig. 1b, upper panel), FN and 
LEF (supplemental Fig. 1b, lower panel), GW9662 dramatically reversed the down regulation of protein of SNA, FN and LEF at $12 \mathrm{~h}$ to a level close to those at $6 \mathrm{~h}$ of TPA treatment. On the transcriptional level, GW9662 (2.5-5.0mM) dose dependently elevated the TPA-induced promoter activation of both full-length promoters, FNpro1938 and LEFpro1897 (containing PPAR-g region) at $12 \mathrm{~h}$ to a level close to FNpro1150 and LEFpro1595 (without PPAR-g region) in both HepG2 (Fig. 4a) and HCC340 (Fig. 4b). To validate the negative regulatory role of PPAR-g, we investigated whether it is also involved in the SNA-mediated MMP9 and ZEB1 upregulation as reported previously [17]. Interestingly, TPA-induced promoter activation of fulllength promoter of MMP9 and ZEB1 (MMP9pro1920 and ZEB1pro2052, containing PPAR-g) were also lower than those of shorter promoter fragments lacking PPAR-g region but contained the TPA-responsive SNA motif (MMP9pro950 and ZEB1 pro1079) [17] in both HepG2 (supplemental Fig. 4a) and HCC340 (supplemental Fig. 4b). As expected, cotreatment of GW9662 (2.5-5.0 mM) elevated TPA-induced promoter activation of full-length promoter of MMP9pro1920 and ZEB1pro2052 (containing PPAR-g region) close to that of MMP9pro950 and ZEB1 pro1079 (without PPAR-g region) in a dose dependent manner (supplemental Fig. 4a, b). However, cotreatment of GW9662 has no rescue effect on TPA-induced promoter activation of the aforementioned full-length promoters at $4 \mathrm{~h}$ when PPAR-g was not yet induced (supplemental Fig. 4c). Consistently, the downregulation of MMP9 and ZEB1 protein in TPA-treated $\mathrm{HCC} 340$ at $12 \mathrm{~h}$ can be rescued by co-treatment of GW9926 to a level close to those at $6 \mathrm{~h}$ (supplemental Fig. 1b, lower panel). Moreover, overexpression of PPAR-g (using a PPAR-g expression plasmid, p-PPAR-g) suppressed the TPA-induced activations of full-length FN and LEF promoters, FNpro1938 and LEFpro1897, but not 5'-truncated mutants FNpro568 and LEFpro1231 (without PPAR-g region) by 60-70\% (Fig. 4c). Prior transfection of p-PPAR-g also prevented TPA-induced activation of full-length promoter of FN, LEF, MMP9 and ZEB1 (FNpro1938, LEFpro1897, MMP9pro1920 and ZEB1pro2052, respectively) at 12 $\mathrm{h}$ in $\mathrm{HCC} 340$ by $40-50 \%$ (Fig. 4d). The same phenomenon was also observed in HepG2 (data not shown). On the contrary, full-length promoters of FN, LEF, MMP9 and ZEB1 with alteration (AAAGG or CCTTT®AGTCT) in PPAR-g regions (FNpro1938*PPAR-g, LEFpro1897*PPAR-g, MMP9pro1920*PPAR-g and ZEB1 pro2052*PPAR-g) exhibited higher TPA-induced promoter activity at $12 \mathrm{~h}$ by 2.0-6.0-fold, compared with each of wild type full-length promoters in both HepG2 (Fig. 4e) and HCC340 (Fig. 4f).

In summary, PPAR-g is responsible for the negative feedback against the SNA-upregulated transcription for FN, LEF, MMP9 and ZEB1 at late stage of TPA treatment.

\section{ChIP and EMSA assay validated the binding of key transcription factors on putative regions}

Thus far, it appears that SNA coupled with EGR1/SP1 activate transcription of the aforementioned mesenchymal genes, and PPAR-g plays as a negative feedback role, whether the indicated putative regions can be bound by the relevant transcriptional factors in these processes was examined, using ChIP assay. As shown in Fig. 5a (upper panel), TPA can induce binding of SNA on a FN promoter fragment (FN280), containing sequences of the critical SNA coupled with EGR1/SP1 region, at $4 \mathrm{~h}$, further increased at $6 \mathrm{~h}$ and returned to basal level at $12 \mathrm{~h}$ in HCC340. Also, TPA can induce binding of EGR 1 on the same promoter fragment at 2-4 h, further increased at $6 \mathrm{~h}$ and declined at $12 \mathrm{~h}$. In addition, TPA can induce sustained binding of SP1 on the same fragment during 4-12 h (Fig. 5a, upper panel). Similarly, 
TPA-induced binding of SNA, EGR1 and SP1 on the LEF promoter fragment (LEF280) containing the critical SNA coupled with EGR1/SP1 region begin at $2 \mathrm{~h}$, further increased at $4 \mathrm{~h}$ and gradually declined during 6-12 h (Fig. 5a, lower panel). Moreover, GW9662 recovered the binding of SNA on FN280 and LEF280 at 12h (Fig. 5a, last lane), consistent with the rescue effect of this PPAR-g inhibitor on TPAinduced promoter activation (Fig. 4b) and expression (supplemental Fig. 1) of both genes at $12 \mathrm{~h}$ time point. Moreover, double ChIP assay validated the association of SNA with EGR1 (by $1^{\text {st }}$ ChIP EGR1, $2^{\text {nd }}$ ChIP SNA), and SNA with SP1 (by $1^{\text {st }}$ ChIP SP1, $2^{\text {nd }}$ ChIP SNA) on FN280 at $4 \mathrm{~h}$, further increased at $6 \mathrm{~h}$ and declined at $12 \mathrm{~h}$ (Fig. 5b, upper panel). Similarly, TPA induced association of SNA with EGR1, and SNA with SP1 at $2 \mathrm{~h}$ on LEF280, further increased at $4-6 \mathrm{~h}$ and declined at $12 \mathrm{~h}$ on LEF promoter (Fig. 5b, lower panel). Moreover, the ChIP and double ChIP assay for binding of the aforementioned transcriptional factors on both promoters were quantitatively analyzed by Q-PCR. As shown in Fig. $5 \mathrm{c}$ (upper left panel), TPA can induce binding of SNA and EGR1 on FN280 by 4.2- and 8.8-fold at $4 \mathrm{~h}$, further increased at $6 \mathrm{~h}$ by 17 - and 20 -fold and returned to 2 and 4 -fold of basal level at $12 \mathrm{~h}$ in HCC340 whereas binding of SP1 on FN280 can be induced at $2 \mathrm{~h}$ by 3.0-fold, increased to 8.0 -fold at $4 \mathrm{~h}$ and sustained to $12 \mathrm{~h}$. Similarly, TPA can induce binding of SNA, EGR1 and SP1 on LEF280 at $2 \mathrm{~h}$ by 1.5-2.0-fold, increased to 3.5 -fold at $4 \mathrm{~h}$, significantly decreased at $6 \mathrm{~h}$ and returned to basal at $12 \mathrm{~h}$ (Fig. $5 \mathrm{c}$, lower left panel). Also, double ChIP assay demonstrated 5.5- and 8.5-fold increase of association of (SNA with EGR1) and (SNA with SP1) on FN280, respectively, at 6 h of TPA treatment (Fig. 5c, upper right panel). Similarly, TPA can induce association of (SNA with EGR1) and (SNA with SP1) on LEF280 by 3.5- and 3.0-fold (Fig. 5c, lower right panel), respectively, at $6 \mathrm{~h}$. Moreover, the decrease of SNA binding on both FN280 and LEF280 at $12 \mathrm{~h}$ can be rescued by cotreatment with GW9662 to those at 6 and 4h, respectively (Fig. 5c, left panel, last bar). On the other hand, TPA can induce binding of PPAR-g on the fragments containing putative region of PPAR-g on FN, LEF, MMP9 and ZEB1 promoter, FN290, LEF230, MMP-9 280, ZEB1 200, respectively, with maximal induction during 6-12h (Fig. 5d). As expected, TPA-induced binding of PPAR-g on the aforementioned promoter fragments can be greatly suppressed by GW9926 at $12 \mathrm{~h}$ (Fig. 5d).

We further confirmed the binding of SNA on their putative region in vitro by EMSA. Nuclear extract of HCC340 treated with TPA at different time points were incubated with biotin labelled probe containing the SNA binding motif on FN promoter (FN-Prob). As shown in Fig. 6a, a DNA-protein complex (revealed as a band shift) was observed in the time zero group. This was increased at 4 and $6 \mathrm{~h}$ by 1.5 - and 2.2-fold, respectively, and declined at $12 \mathrm{~h}$. Addition of 200 -fold of the unlabeled wild type but not mutant type of probe reduced the amount of DNA-protein complex by $80-90 \%$ at $6 \mathrm{~h}$. Moreover, preincubation of the EMSA mixture with SNA antibody but not IgG control resulted in a supershift of the DNA-protein complex, validating SNA was the protein bound with the DNA probe. The same phenomenon was also observed in EMSA of the DNA probe containing the critical SN1 binding motif on LEF promoter (LEF-Prob). As demonstrated in Fig. 6b, TPA induced band shift of the DNA-protein complex maximally at $4 \mathrm{~h}$, and gradually decreased at 6-12 h. As expected, the TPA-induced band shift of the DNA-protein complex at $4 \mathrm{~h}$ can be competed by unlabeled wild type but not mutant type probe (Fig. 6b). Moreover, a supper band shift of the protein DNA complex can also be observed if EMSA mixture from $4 \mathrm{~h}$-TPA sample was preincubated with SNA Ab but not IgG control (Fig. 6b). 


\section{COX2 and COL1A1 were potentially transcriptionally upregulated by SN as the aforementioned mesenchymal gene.}

Thus far, we have demonstrated four of the mesenchymal genes FN, LEF, MMP9 and ZEB1 transcriptionally upregulated by SNA in a same manner, ie, direct binding of SNA coupled with EGR1/SP1 on their putative regions, which can be negatively feedbacked by PPAR-g. To validate whether this can be a general model, we screen the mesenchymal genes that can be upregulated by SNA from PubMed and examine whether they contain the aforementioned SNA binding motif (TCACA) coupled with a downstream EGR1/SP1 overlapping region and an upstream PPAR-g binding motif on the promoter sequences, 2000 bp upstream of translational start site by using gene bank in NCBI. Among them, ten of the well-known mesenchymal genes were proposed (Table 1). Most of the candidate mesenchymal genes such as COX2, vimentin, vitronectin, COL1A1, a-SMA, N-cadherin, Twist1 have been reported to be upregulated by SNA involved in tumor progression. For example, COX2, which greatly correlates with malignancy, can be upregulated by SNA in head and neck squamous cell carcinomas [24]. To begin with, we validated whether COX2 and COL1A1 can be induced by TPA. As shown in Q RT-PCR (supplemental Fig. 5), TPA increased mRNA of both COX2 and COL $1 \mathrm{~A} 1 \mathrm{~h}$ at $2 \mathrm{~h}$ by $1.5-2.0$-fold, further increased at $4 \mathrm{~h}$ and reach maximum at $6 \mathrm{~h}$ by 8 and 10 -fold, respectively, and finally declined to basal level at $12 \mathrm{~h}$. Moreover, GW9662 significantly rescued the downregulation of mRNA of both COX2 and COL1A1 at 12h. These suggested that while SNA is essential for gene expression of COX2 and COL1A1, PPAR-g played as a negatively feedback regulator, the same mechanisms as we observed in FN, LEF, MMP9 and ZEB1. We further investigated whether transcription regulation of COX2 and COL1A1 is also the same using deletion mapping for promoter analysis. According to the Genomatix software, there are one proposed SNA binding region and a downstream EGR1/SP1, locate on promoter of COX2 (-1007 to -502 bp upstream of the translation start site) and COL1A1 ( -1122 to -934 bp upstream of the translation start site) (supplemental Fig. 3c, d). Also, there are one putative PPAR-g binding region upstream of SNA region, locating on promoter of COX2 (-1560 to -979 bp upstream of the translation start site) and COL1A1 (-1969 to -1090 bp upstream of the translation start site) (supplemental Fig. 3c, d). Accordingly, we constructed the full-length promoter plasmid of COX2 (COX2pro1560) and COX2pro1228 containing PPAR-g coupled with one SNA motif and EGR1/SP1 overlapping binding regions. Also, COX2pro979, 5' end truncated mutants lacking PPAR-g binding region, and COX2pro870 lacking PPAR-g and one SNA region were obtained. In addition, COX2pro362 and COX2pro175, with deletion of PPAR-g, one SNA region and the downstream EGR1/SP1 overlapping region, were also included. Strikingly, we found a $40-45 \%$ higher TPA-induced promoter activity of COX2pro979 (without PPAR-g region) compared with full-length COX2pro1560 and 1228 (with PPAR-g region) whereas the TPA-induced promoter activity of COX2pro870 and COX2pro362 decreased by 50 and 80\%, respectively, compared with COX2pro979 in HCC340 (Fig. 7a, upper panel). Moreover, GW9662 (at 2.5 and $5.0 \mathrm{mM}$ ) dose-dependently elevated the TPA-induced promoter activity of COX2pro1560 by 33 to $45 \%$, a level close to that of COX2pro979 (Fig. 7b, upper panel). The deletion mapping analysis for COL1A1 revealed the similar results. As demonstrated in Fig. 7a (lower panel), the TPA-induced promoter activity of full-length promoter of COL1A1 (COL1A1pro1969) containing PPAR-g and one SNA region was lower than the deleted mutant COL1A1pro1090 (lacking the 
5' PPAR-g region) by $46 \%$, whereas the activity of COL1A1pro644 without both SNA and PPAR-g regions was lower than that of COL1A1pro1090 by $60 \%$. Moreover, GW9662 (at 2.5 and $5.0 \mathrm{mM}$ ) dosedependently elevated the TPA-induced promoter activity of COL1A1pro1969 by 39 to $46 \%$, a level close to COL1A1 pro1090 (Fig. 7a, lower panel). Thus, we suggested SNA-mediated upregulation of promoter activation COX2 and COL1A1 is also negatively feed backed by PPAR-g, potentially in the same way as that of the aforementioned mesenchymal genes.

\section{Discussion}

\section{Multifaceted mechanisms for SNA to upregulate target gene expression}

In the past decades, it appears that the mechanisms by which SNA upregulates gene expression of mesenchymal genes were more complicated than it downregulated epithelial markers. As demonstrated in this report, SNA upregulate mesenchymal genes such as FN, LEF, MMP9 and ZEB1 by directly binding on a consensus motif to activate target promoters in HCC. However, a lot of previous studies indicated SNA also upregulate mesenchymal markers in an indirect fashion. For examples, SNA mediated the TGFb-induced MMP9 activation by promoting the binding of SP-1/Ets-1 and nuclear factor kappaB (NFkappaB) to the proximal and distal promoter regions, respectively [15], in MDCK cell. Also, SNA upregulated transcription of ZEB1 by elevating gene expression of Twist and triggering the nuclear translocation of Ets1 [16]. Recently, it is emerging that SNA-regulated gene expression involves negative feedback circuit established by the cross talk between SNA and non-coding RNAs, including miRNAs, long non-coding RNAs, and circular RNAs $[25,26]$. Taken together, there are multifaceted mechanisms for SNA to upregulate target gene expression.

\section{SNA directly upregulated transcription of FN and LEF in tumor progression}

Previously, the role of SNA in upregulating transcription of FN and LEF has been intensively studied in different contexts. SNA can mediate TGFb-triggered LEF expression for EMT in MDCKII cells [27]. Overexpression of SNA elevated FN to trigger EMT of retinal pigment epithelial (RPE) cell involved in proliferative vitreoretinopathy [28]. Also, SNA mediated FGF2-dependent expression of FN involved in endothelial-mesenchymal transition leading to retrocorneal membrane formation and blindness [29]. However, the detailed mechanisms by which SNA directly transactivates FN and LEF has not been well established yet. One previous study demonstrated that SNA coupled with the p65 subunit of NF-KB and PARP1 bound to the FN1 promoter at proximal $(-236 /+72)$ region for activating FN1 transcription in melanoma cell [30]. Herein, we found SNA coupled with EGR1 and SP1 upregulate both FN and LEF via binding to a distal region (-700 to -547 and -1300 to -1211 bp, respectively) containing a critical TCACA sequence (proposed SNA motif) adjacent to an EGR1-SP1 overlapping region. This mechanism is in similar with what we have observed in the SNA-upregulated MMP9 and ZEB1 transcription [17].

\section{PPAR-y exerted a negative feedback on SNA upregulated mesenchymal gene}


PPAR-y was well known to suppress EMT [31-34] and inhibit metastases of HCC [35]. PPAR-y can also affect transcription of mesenchymal genes known to be suppressed by SNA. For example, PPAR- $y$ prevents the TGF- $\beta$-induced vimentin, $\mathrm{N}$-cadherin, fibronectin required for metastasis of lung cancer cells [32]. In this study, we found PPAR-y can suppress the SNA-upregulated transcription of FN, LEF, MMP9 and ZEB1 at later stage of TPA treatment (Fig. 4 and Fig. 5) suggesting PPAR-g play as a negative feedback regulator.

\section{Mechanisms for SNA to directly upregulate mesenchymal gene transcription}

Thus far, we have demonstrated four of the mesenchymal genes, MMP9, ZEB1, FN and LEF transcriptionally upregulated by SNA in a same mechanism, ie, direct binding of SNA coupled with EGR1/SP1 on their putative regions, which can be negatively feed backed by PPAR-g. Remarkably, the promoter of most mesenchymal genes known to be upregulated by SNA (Table 1) contain the same sequence architecture: SNA binding motif coupled with downstream E/S overlapping and upstream PPAR-g region. Among them, COX2 and COL1A1 were found to be potentially regulated as the same way (Fig. 7).

\section{Conclusion}

In summary, we proposed a general model for SNA to upregulate transcription of transcription of mesenchymal genes via collaboration with EGR1/SP1 and negatively feed backed by PPAR-g. In the future, this model will be validated after more of the candidate mesenchymal genes are found to be transcriptionally upregulated by SNA in the same way.

\section{Abbreviations}

SNA: Snail; MMP9: matrix metalloproteinases 9; ZEB1: zinc finger E-box binding homeobox 1; TPA: the phorbol ester tumor promoter 12-0-tetradecanoyl-phorbol 13-acetate; EGR1: Early Growth Response 1; SP1: Proximal specificity protein 1; FN: fibronectin and LEF: lymphoid enhancer-binding factor, PPAR-Y: peroxisome proliferator-activated receptor $-\gamma$; COX2: cyclooxygenase 2; COL1A1: collagen type I alpha 1 chain; FOXA2: Forkhead box protein A2; PM: point mutation; ChIP: chromatin immunoprecipitation; EMSA: electrophoresis mobility shift assay; EMT: epithelial mesenchymal transition; HCC: hepatocellular carcinoma.

\section{Declarations}

\section{Funding}

This study was financially supported by the project of Tzu Chi Medical Mission Project (TCMMP108-0302) granted by Tzu Chi Medical Foundation and Ministry of Science and Technology (MOST 108-2320-B320-003). 


\section{Ethics approval}

Not applicable.

\section{Consent for publication}

Not applicable.

Competing interests

The authors have declared that no competing interest exists.

\section{Availability of data and materials}

The datasets during and/or analyzed during the current study available from the corresponding author on reasonable request.

\section{Authors's contributions}

TML performed most of the experiments. WSW and RIY conceived, designed, performed experiments and wrote paper. WSW supervised the project. CCC constructed all the promoter plasmids used in the study. YCC, MCL and HH Chang provide the materials and equipment for the required experiments. They also reviewed and gave suggestions for manuscript preparation.

\section{Acknowledgments}

We thank Miss. Lin-Ching Hui for the technical assistance.

\section{References}

1. Gupta GP, Massagué J. Cancer Metastasis: Building a Framework. Cell. 2006;127:679-95.

2. Chen D, Zheng X, Jiao X, Gao Y, Liang J. Transcriptional repressor snail and metastasis in hepatocellular carcinoma. Hepatogastroenterology. 2012;59:1359-65.

3. Jiao W, Miyazaki K, Kitajima Y. Inverse correlation between E-cadherin and Snail expression in hepatocellular carcinoma cell lines in vitro and in vivo. Br J Cancer. 2002;86:98-101.

4. Meng F Di, Wei JC, Qu K, Wang ZX, Wu QF, Tai MH, et al. FoxM1 overexpression promotes epithelialmesenchymal transition and metastasis of hepatocellular carcinoma. World J Gastroenterol. 2015;21:196-213.

5. Zhang M, Dong X, Zhang D, Chen X, Zhu X. High expression of Snail and NF-KB predicts poor survival in Chinese hepatocellular carcinoma patients. Oncotarget. 2017;8:4543-8.

6. Deng G, Zeng S, Ma J, Zhang Y, Qu Y, Han Y, et al. The anti-tumor activities of Neferine on cell invasion and oxaliplatin sensitivity regulated by EMT via Snail signaling in hepatocellular carcinoma. Sci Rep. 2017;7. 
7. Berghoff AS, Ricken G, Widhalm G, Rajky O, Dieckmann K, Birner P, et al. Tumour-infiltrating lymphocytes and expression of programmed death ligand 1 (PD-L1) in melanoma brain metastases. Histopathology. 2015;66:289-99.

8. Tang Y, Lv P, Sun Z, Han L, Zhou W. 14-3-3 $\beta$ promotes migration and invasion of human hepatocellular carcinoma cells by modulating expression of $\mathrm{mmp} 2$ and $\mathrm{mmp} 9$ through PI3K/Akt/NFKB pathway. PLoS One. 2016;11.

9. Chen J, Yang P, Yang J, Wen Z, Zhang B, Zheng X. GIT1 is a novel prognostic biomarker and facilitates tumor progression via activating ERK/MMP9 signaling in hepatocellular carcinoma. Onco Targets Ther. 2015;8:3731-42.

10. Yan XL, Jia YL, Chen L, Zeng Q, Zhou JN, Fu CJ, et al. Hepatocellular carcinoma-associated mesenchymal stem cells promote hepatocarcinoma progression: Role of the S100A4-miR155SOCS1-MMP9 axis. Hepatology. 2013;57:2274-86.

11. Hashiguchi M, Ueno S, Sakoda M, lino S, Hiwatashi K, Minami K, et al. Clinical implication of ZEB-1 and E-cadherin expression in hepatocellular carcinoma (HCC). BMC Cancer. 2013;13:572.

12. Liu TA, Jan YJ, Ko BS, Liang SM, Chen SC, Wang J, et al. 14-3-3ع Overexpression Contributes to Epithelial-Mesenchymal Transition of Hepatocellular Carcinoma. PLoS One. 2013;8.

13. Herranz N, Pasini D, Díaz VM, Francí C, Gutierrez A, Dave N, et al. Polycomb Complex 2 Is Required for E-cadherin Repression by the Snail1 Transcription Factor. Mol Cell Biol. 2008;28:4772-81.

14. Tong ZT, Cai MY, Wang XG, Kong LL, Mai SJ, Liu YH, et al. EZH2 supports nasopharyngeal carcinoma cell aggressiveness by forming a co-repressor complex with HDAC1/HDAC2 and Snail to inhibit E-cadherin. Oncogene. 2012;31:583-94.

15. Jordà M, Olmeda D, Vinyals A, Valero E, Cubillo E, Llorens A, et al. Upregulation of MMP-9 in MDCK epithelial cell line in response to expression of the Snail transcription factor. J Cell Sci. 2005;118:3371-85.

16. Dave N, Guaita-Esteruelas S, Gutarra S, Frias À, Beltran M, Peiró S, et al. Functional cooperation between snail 1 and twist in the regulation of ZEB1 expression during epithelial to mesenchymal transition. J Biol Chem. 2011;286:12024-32.

17. Wu WS, You RI, Cheng CC, Lee MC, Lin TY, Hu CT. Snail collaborates with EGR-1 and SP-1 to directly activate transcription of MMP 9 and ZEB1. Sci Rep. 2017;7.

18. Hu CT, Chang TY, Cheng CC, Liu CS, Wu JR, Li MC, et al. Snail associates with EGR-1 and SP-1 to upregulate transcriptional activation of p15INK4b. FEBS J. 2010;277:1202-18.

19. Kaufhold S, Bonavida B. Central role of Snail1 in the regulation of EMT and resistance in cancer: A target for therapeutic intervention. J Exp Clin Cancer Res. 2014;33.

20. Schmitt-Graeff A, Ertelt-Heitzmann V, Allgaier HP, Olschewski M, Nitschke R, Haxelmans S, et al. Coordinated expression of cyclin D1 and LEF-1/TCF transcription factor is restricted to a subset of hepatocellular carcinoma. Liver Int. 2005;25:839-47.

21. Wu JR, Hu CT, You RI, Pan SM, Cheng CC, Lee MC, et al. Hydrogen peroxide inducible clone-5 mediates reactive oxygen species signaling for hepatocellular carcinoma progression. Oncotarget. 
2015;6:32526-44.

22. Choudhary R, Li H, Winn RA, Sorenson AL, Weiser-Evans MCM, Nemenoff RA. Peroxisome proliferator-activated receptor-y inhibits transformed growth of non-small cell lung cancer cells through selective suppression of snail. Neoplasia. 2010;12:224-34.

23. Lee YH, Kim SH, Lee YJ, Kang ES, Lee BW, Cha BS, et al. Transcription factor Snail is a novel regulator of adipocyte differentiation via inhibiting the expression of peroxisome proliferatoractivated receptor $\gamma$. Cell Mol Life Sci. 2013;70:3959-71.

24. Lyons JG, Patel V, Roue NC, Fok SY, Soon LL, Halliday GM, et al. Snail up-regulates proinflammatory mediators and inhibits differentiation in oral keratinocytes. Cancer Res. 2008;68:4525-30.

25. Skrzypek K, Majka M. Interplay among SNAIL transcription factor, microRNAs, long non-coding RNAs, and circular RNAs in the regulation of tumor growth and metastasis. Cancers (Basel). 2020.

26. Fumagalli MR, Lionetti MC, Zapperi S, La Porta CAM. Cross-Talk Between circRNAs and mRNAs Modulates MiRNA-mediated Circuits and Affects Melanoma Plasticity. Cancer Microenviron. 2019;12:95-104.

27. Medici D, Hay ED, Goodenough DA. Cooperation between snail and LEF-1 transcription factors is essential for TGF- $\beta 1$-induced epithelial-mesenchymal transition. Mol Biol Cell. 2006;17:1871-9.

28. Li H, Li M, Xu D, Zhao C, Liu G, Wang F. Overexpression of Snail in retinal pigment epithelial triggered epithelial-mesenchymal transition. Biochem Biophys Res Commun. 2014;446:347-51.

29. Lee JG, Jung E, Heur M. Fibroblast growth factor 2 induces proliferation and fibrosis via SNAl1mediated activation of CDK2 and ZEB1 in corneal endothelium. J Biol Chem. 2018;293:3758-69.

30. Stanisavljevic J, Porta-de-la-Riva M, Batlle R, de Herreros AG, Baulida J. The p65 subunit of NF-KB and PARP1 assist Snail1 in activating fibronectin transcription. J Cell Sci. 2011;124:4161-71.

31. Yumin C, Qiong L, Zibo X, Wei L, Li C, Zuying X. Telmisartan counteracts TGF- $\beta 1$ induced epithelial-tomesenchymal transition via PPAR- $\gamma$ in human proximal tubule epithelial cells. Int J Clin Exp Pathol. 2012;5:522-9.

32. Reka AK, Kurapati H, Narala VR, Bommer G, Chen J, Standiford TJ, et al. Peroxisome proliferatoractivated receptor-g activation inhibits tumor metastasis by antagonizing smad3-mediated epithelialmesenchymal transition. Mol Cancer Ther. 2010;9:3221-32.

33. Wei J, Li Z, Yuan F. Evodiamine might inhibit TGF-beta1-induced epithelial-mesenchymal transition in NRK52E cells via Smad and PPAR-gamma pathway. Cell Biol Int. 2014;38:875-80.

34. Yang P, Chen S, Zhong G, Kong W, Wang Y. Agonist of PPAR-y reduced epithelial-mesenchymal transition in eosinophilic chronic rhinosinusitis with nasal polyps via inhibition of high mobility group box1. Int J Med Sci. 2019;16:1631-41.

35. Shen B, Chu ESH, Zhao G, Man K, Wu CW, Cheng JTY, et al. PPARgamma inhibits hepatocellular carcinoma metastases in vitro and in mice. Br J Cancer. 2012;106:1486-94.

36. Yamanaka O, Miyazaki KI, Kitano A, Saika S, Nakajima Y, Ikeda K. Suppression of injury-induced conjunctiva scarring by peroxisome proliferator-activated receptor $y$ gene transfer in mice. Investig 
Ophthalmol Vis Sci. 2009;50:187-93.

37. Guo B, Koya D, Isono M, Sugimoto T, Kashiwagi A, Haneda M. Peroxisome Proliferator-Activated Receptor-y Ligands Inhibit TGF- $\beta 1$-Induced Fibronectin Expression in Glomerular Mesangial Cells. Diabetes. 2004;53:200-8.

38. Baritaki S, Chapman A, Yeung K, Spandidos DA, Palladino M, Bonavida B. Inhibition of epithelial to mesenchymal transition in metastatic prostate cancer cells by the novel proteasome inhibitor, NPI0052: Pivotal roles of Snail repression and RKIP induction. Oncogene. 2009;28:3573-85.

39. Kwon CH, Park HJ, Choi JH, Lee JR, Kim HK, Jo H jae, et al. Snail and serpinA1 promote tumor progression and predict prognosis in colorectal cancer. Oncotarget. 2015;6:20312-26.

40. Liu C, Yao J, Mercola D, Adamson E. The transcription factor EGR-1 directly transactivates the fibronectin gene and enhances attachment of human glioblastoma cell line U251. J Biol Chem. 2000;275:20315-23.

41. Hu J, Shan Z, Hu K, Ren F, Zhang W, Han M, et al. MiRNA-223 inhibits epithelial-mesenchymal transition in gastric carcinoma cells via Sp1. Int J Oncol. 2016;49:325-35.

42. Hetzel M, Walcher D, Grüb M, Bach H, Hombach V, Marx N. Inhibition of MMP-9 expression by PPARy activators in human bronchial epithelial cells. Thorax. 2003;58:778-83.

43. Liu J, Sakurai R, Rehan VK. PPAR-y agonist rosiglitazone reverses perinatal nicotine exposureinduced asthma in rat offspring. Am J Physiol - Lung Cell Mol Physiol. 2015;308:L788-96.

44. Sakurai R, Lee C, Shen H, Waring AJ, Walther FJ, Rehan VK. A Combination of the Aerosolized PPAR-Y Agonist Pioglitazone and a Synthetic Surfactant Protein B Peptide Mimic Prevents HyperoxiaInduced Neonatal Lung Injury in Rats. Neonatology. 2018;113:296-304.

45. Medici D, Hay ED, Olsen BR. Snail and slug promote epithelial-mesenchymal transition through $\beta$ catenin-T-cell factor-4-dependent expression of transforming growth factor- $\beta 3$. Mol Biol Cell. 2008;19:4875-87.

46. Guaita S, Puig I, Francí C, Garrido M, Domínguez D, Batlle E, et al. Snail induction of epithelial to mesenchymal transition in tumor cells is accompanied by MUC1 repression and ZEB1 expression. J Biol Chem. 2002;277:39209-16.

47. Di Gregorio J, Sferra R, Speca S, Vetuschi A, Dubuquoy C, Desreumaux P, et al. Role of glycogen synthase kinase-3 $\beta$ and PPAR-y on epithelial-to-mesenchymal transition in DSS-induced colorectal fibrosis. PLoS One. 2017;12.

48. Scoditti E, Massaro M, Carluccio MA, Distante A, Storelli C, De Caterina R. PPAR y agonists inhibit angiogenesis by suppressing PKCa-and CREB-mediated COX-2 expression in the human endothelium. Cardiovasc Res. 2010;86:302-10.

49. Zhang XH, Liang X, Wang TS, Liang XH, Zuo RJ, Deng WB, et al. Heparin-binding epidermal growth factor-like growth factor (HB-EGF) induction on Snail expression during mouse decidualization. Mol Cell Endocrinol. 2013;381:272-9.

50. Osorio LA, Farfán NM, Castellón EA, Contreras HR. SNAIL transcription factor increases the motility and invasive capacity of prostate cancer cells. Mol Med Rep. 2016;13:778-86. 
51. Wu Y, Zhang X, Zehner ZE. c-Jun and the dominant-negative mutant, TAM67, induce vimentin gene expression by interacting with the activator Sp1. Oncogene. 2003;22:8891-901.

52. Zhao J, Geng L, Duan G, Xu W, Cheng Y, Huang Z, et al. REC8 inhibits EMT by downregulating EGR1 in gastric cancer cells. Oncol Rep. 2018;39:1583-90.

53. Hanson AM, Gambill J, Phomakay V, Staten CT, Kelley MD. 9-cis-Retinoic acid and troglitazone impacts cellular adhesion, proliferation, and integrin expression in K562 cells. PLoS One. 2014;9.

54. Assani G, Zhou Y. Effect of modulation of epithelial-mesenchymal transition regulators Snail1 and Snail2 on cancer cell radiosensitivity by targeting of the cell cycle, cell apoptosis and cell migration/invasion (Review). Oncol. Lett. 2019. p. 23-30.

55. Škovierová H, Okajčeková T, Strnádel J, Vidomanová E, Halašová E. Molecular regulation of epithelial-to-mesenchymal transition in tumorigenesis (Review). Int. J. Mol. Med. 2018. p. 1187-200.

56. Sun L, Liu Y, Lin S, Shang J, Liu J, Li J, et al. Early growth response gene-1 and hypoxia-inducible factor-1a affect tumor metastasis via regulation of tissue factor. Acta Oncol (Madr). 2013;52:84251.

57. Tan X, Dagher H, Hutton CA, Bourke JE. Effects of PPARY ligands on TGF- $\beta 1$-induced epithelialmesenchymal transition in alveolar epithelial cells. Respir Res. 2010;11:21.

58. Wei J, Zhu H, Komura K, Lord G, Tomcik M, Wang W, et al. A synthetic PPAR-y agonist triterpenoid ameliorates experimental fibrosis: PPAR-y-independent suppression of fibrotic responses. Ann Rheum Dis. 2014;73:446-54.

59. Peng CY, Liao YW, Lu MY, Yang CM, Hsieh PL, Yu CC. Positive feedback loop of SNAIL-IL-6 mediates myofibroblastic differentiation activity in precancerous oral submucous fibrosis. Cancers (Basel). 2020;12:1-14.

60. Pinto MT, Melo FUF, Malta TM, Rodrigues ES, Plaça JR, Silva WA, et al. Endothelial cells from different anatomical origin have distinct responses during SNAIL/TGF- $\beta 2$-mediated endothelialmesenchymal transition. Am J Transl Res. 2018;10:4065-81.

61. Gaut L, Robert N, Delalande A, Bonnin MA, Pichon C, Duprez D. EGR1 regulates transcription downstream of mechanical signals during tendon formation and healing. PLoS One. 2016;11.

62. Duval E, Bouyoucef $M$, Leclercq S, Baugé $C$, Boumédiene K. Hypoxia inducible factor 1 alpha downregulates type i collagen through $\mathrm{Sp} 3$ transcription factor in human chondrocytes. IUBMB Life. 2016;68:756-63.

63. Zhao M, Chen Y, Ding G, Xu Y, Bai M, Zhang Y, et al. Renal tubular epithelium-targeted peroxisome proliferatoractivated receptor- $\gamma$ maintains the epithelial phenotype and antagonizes renal fibrogenesis. Oncotarget. 2016;7:64690-701.

64. Wang W, Liu F, Chen N. Peroxisome proliferator-activated receptor-y (PPAR- $\gamma$ ) agonists attenuate the profibrotic response induced by TGF- $\beta 1$ in renal interstitial fibroblasts. Mediators Inflamm. 2007;2007.

65. Lee SW, Won JY, Kim WJ, Lee J, Kim KH, Youn SW, et al. Snail as a potential target molecule in cardiac fibrosis: Paracrine action of endothelial cells on fibroblasts through snail and CTGF Axis. Mol 
Ther. 2013;21:1767-77.

66. Hu F, Xue M, Li Y, Jia YJ, Zheng ZJ, Yang YL, et al. Early Growth Response 1 (Egr1) Is a Transcriptional Activator of NOX4 in Oxidative Stress of Diabetic Kidney Disease. J Diabetes Res. 2018;2018:3405695.

67. Li HY, Ju D, Zhang DW, Li H, Kong LM, Guo Y, et al. Activation of TGF- $\beta 1-C D 147$ positive feedback loop in hepatic stellate cells promotes liver fibrosis. Sci Rep. 2015;5.

68. Lu X, Yan C, Huang Y, Shi D, Fu Z, Qiu J, et al. Mouse double minute 2 (MDM2) upregulates Snail expression and induces epithelial-to-mesenchymal transition in breast cancer cells in vitro and in vivo. Oncotarget. 2016;7:37177-91.

69. Wang Y, Liu J, Ying X, Lin PC, Zhou BP. Twist-mediated Epithelial-mesenchymal Transition Promotes Breast Tumor Cell Invasion via Inhibition of Hippo Pathway. Sci Rep. 2016;6.

70. Peng WX, Wan YY, Gong AH, Ge L, Jin J, Xu M, et al. Egr-1 regulates irradiation-induced autophagy through Atg4B to promote radioresistance in hepatocellular carcinoma cells. Oncogenesis. 2017;6.

71. Lu W, Ma YY, Shao QQ, Liang J, Qi TT, Huang Y, et al. ROS/p53/miR-335-5p/Sp1 axis modulates the migration and epithelial to mesenchymal transition of JEG-3 cells. Mol Med Rep. 2020;21:1208-16.

72. Wang Z, Liu Q, Dai W, Hua B, Li H, Li W. Pioglitazone downregulates Twist-1 expression in the kidney and protects renal function of Zucker diabetic fatty rats. Biomed Pharmacother. 2019;118.

73. Zeng Q, Zhang Y, Zhang W, Guo Q. Baicalein suppresses the proliferation and invasiveness of colorectal cancer cells by inhibiting Snail-induced epithelial-mesenchymal transition. Mol Med Rep. 2020;21:2544-52.

\section{Tables}

Table 1 Transcriptional factor binding region on candidate Mesenchymal genes 


\begin{tabular}{|c|c|c|c|}
\hline $\begin{array}{l}\text { Mesenchymal } \\
\text { genes promoter }\end{array}$ & $\begin{array}{l}\text { Proposed } \\
\text { transcription } \\
\text { factors }\end{array}$ & Proposed binding motif & Reference \\
\hline \multirow{3}{*}{ FN } & PPAR-g & -1480 ССТТТ -1474 & {$[36,37]$} \\
\hline & Snail & -576 TCACA -570 & {$[38,39]$} \\
\hline & E/S overlapping & -361 CGGCGGGCGGGCGGGC -344 & {$[40,41]$} \\
\hline \multirow{3}{*}{ MMP9 } & PPAR-g & $\begin{array}{l}1233 \text { AAAGG -1227 } \\
\end{array}$ & {$[32,42]$} \\
\hline & Snail & -818 TCACA -812 & {$[15,17]$} \\
\hline & E/S overlapping & -797 GAGCCССССАСССССС -781 & [17] \\
\hline \multirow{3}{*}{ LEF } & PPAR-g & -1653 CСТTT -1647 & {$[43,44]$} \\
\hline & Snail & -1287 TCACA -1281 & {$[45,46]$} \\
\hline & E/S overlapping & -1196 СССТСАССССССGССТ -1178 & \\
\hline \multirow{3}{*}{ ZEB1 } & PPAR-g & -1981 CCTTT -1975 & [47] \\
\hline & Snail & -1065 TCACA -1059 & [17] \\
\hline & E/S overlapping & -933 AAGAGGGCGGGGAGCG -915 & [17] \\
\hline \multirow{3}{*}{ COX2 } & PPAR-g & -1012 CCTTT -1006 & [48] \\
\hline & Snail & -964 TCACA -958 & [49] \\
\hline & E/S overlapping & -519 ТTCТGСССТСССССGGTA -500 & \\
\hline \multirow{3}{*}{ VIMENTIN } & PPAR-g & $\begin{array}{l}-2449 \text { CСТTT }-2443 \\
\end{array}$ & [32] \\
\hline & Snail & -2318 TCACA -2312 & {$[50]$} \\
\hline & E/S overlapping & -1976 СССССТGCСGССАСС-1960 & {$[51,52]$} \\
\hline \multirow{3}{*}{ VITRONECTIN } & PPAR-g & -2088 CCTTT -2082 & [53] \\
\hline & Snail & -1373 TCACA -1367 & {$[54,55]$} \\
\hline & E/S overlapping & -1238 GCACCCGCCCACCAC -1222 & {$[56]$} \\
\hline \multirow{3}{*}{ COL1A1 } & PPAR-g & -1196 CCTTT -1190 & {$[57,58]$} \\
\hline & Snail & -1072 TCACA -1066 & {$[59,60]$} \\
\hline & E/S overlapping & -994 ССССААТССССАССТС -977 & {$[61,62]$} \\
\hline \multirow{3}{*}{$\alpha-S M A$} & PPAR-g & -808 AAAGG -802 & {$[63,64]$} \\
\hline & Snail & $\begin{array}{l}-689 \text { TGTGA -683 } \\
\end{array}$ & {$[28,65]$} \\
\hline & E/S overlapping & -507 GCTCTCTCCCCGCСCC -490 & {$[66,67]$} \\
\hline \multirow{3}{*}{ N-cadherin } & PPAR-g & -1824 CCTTT -1796 & {$[34,57]$} \\
\hline & Snail & -311 TCACA -305 & {$[68,69]$} \\
\hline & E/S overlapping & -289 CCСССGСССССТСССС -272 & {$[70,71]$} \\
\hline \multirow[t]{3}{*}{ TWIST1 } & PPAR-g & -953 ССТТТ -947 & [72] \\
\hline & Snail & -723 TCACA -717 & [73] \\
\hline & E/S overlapping & -606 CCCCGCGCCCGCCGGA -590 & \\
\hline
\end{tabular}

Table 2. Primers used for ChIP assays 


\begin{tabular}{|c|c|c|}
\hline Gene & Primer sequence & Product size \\
\hline \multirow{2}{*}{ FN280 } & F: 5'GGG AAG GGG GAG CGT CTT3' & \multirow{2}{*}{$280 \mathrm{bp}$} \\
\hline & R: 5'CCC GCC CCA CCC CAC CCG3' & \\
\hline \multirow{2}{*}{ FN290 } & F: 5'TTT GGA GAA AAT AGG TAC3' & \multirow{2}{*}{$290 \mathrm{bp}$} \\
\hline & R: 5'TAA GAT TCC CCC GCC TTG3' & \\
\hline \multirow{2}{*}{ LEF280 } & F: 5'CTC GCC AAG TTG CCT GAT3' & \multirow{2}{*}{$280 \mathrm{bp}$} \\
\hline & R: 5'CTC CCC ACT GCT TCT CCT3' & \\
\hline \multirow{2}{*}{ LEF230 } & F: 5'TAC ATC CCG TGG TGA GAA3' & \multirow{2}{*}{$230 \mathrm{bp}$} \\
\hline & R: 5'CAT TGC TCA ACT ATT AAG3' & \\
\hline \multirow{2}{*}{ MMP9 280} & F: 5'ATA GAC CCT GCC CGA TGC3' & \multirow{2}{*}{$280 \mathrm{bp}$} \\
\hline & R: 5'CTT GGA ATC ACC AAA CCA3' & \\
\hline \multirow{2}{*}{ ZEB1 200} & F: 5'AAA ATG CTA TTT GTA ATA3' & \multirow{2}{*}{$200 \mathrm{bp}$} \\
\hline & R: 5'TTC TTC CTC CCT TTT TTT3' & \\
\hline \multirow{2}{*}{ GADPH } & F: 5'TAC TAG CGG TTT TAC GGG CG3' & \multirow{2}{*}{$166 \mathrm{bp}$} \\
\hline & R: 5'TCG AAC AGG AGG AGC AGA GAG CGA3' & \\
\hline
\end{tabular}

Table 3. Primers used for RT-PCR and real time PCR in gene expression analysis

\begin{tabular}{|c|c|c|}
\hline Gene & Primer sequence & $\begin{array}{l}\text { Product } \\
\text { size }\end{array}$ \\
\hline \multirow[t]{2}{*}{ Snail } & $\begin{array}{l}\text { F: 5'AAGC TTCC ATGG CGCG CTCT TTCC TCGT CAGG AAGC } \\
\text { CC3' }\end{array}$ & \multirow[t]{2}{*}{$795 \mathrm{bp}$} \\
\hline & $\begin{array}{c}\text { R: 5'GGAT CCTC AGCG GGGA CATC CTGA GCAG CCGG ACTC } \\
\text { TTG3' }\end{array}$ & \\
\hline \multirow[b]{2}{*}{ FN } & F: 5'AAG GAG AAG ACC GGA CCA AT3' & \multirow[t]{2}{*}{$614 \mathrm{bp}$} \\
\hline & R: 5'GGC TTG ATG GTT CTC TGG AT3' & \\
\hline \multirow{2}{*}{ LEF1 } & F: 5'TGG CAG CCC TAT TTC AGT TT3' & \multirow[t]{2}{*}{$334 \mathrm{bp}$} \\
\hline & R: 5'CAA AGG CTG TGC TTG CTT TT3' & \\
\hline \multirow[b]{2}{*}{ COX2 } & F: 5'CGG TGA AAC TCT GGC TAG ACA G3' & \multirow[t]{2}{*}{156} \\
\hline & R: 5'GCA AAC CGT AGA TGC TCA GGG A3' & \\
\hline \multirow[b]{2}{*}{ COL1A1 } & F: 5'TCT GCG ACA ACG GCA AGG TG3' & \multirow[t]{2}{*}{146} \\
\hline & R: 5'GAC GCC GGT GGT TTC TTG GT3' & \\
\hline \multirow[b]{2}{*}{ PPAR- $\gamma$} & F: 5'TTG TTC CAG GGA AAT TCA CTG C3' & \multirow[t]{2}{*}{171} \\
\hline & R: 5'CGC CGT AAA TTA TTT CTA AAC C3' & \\
\hline \multirow[b]{2}{*}{ GADPH } & F: 5’ACC ACA GTC CAT GCC ATC AC3' & \multirow[t]{2}{*}{$450 \mathrm{bp}$} \\
\hline & R: 5'TCC ACC ACC CTG TTG CTG TA3' & \\
\hline
\end{tabular}


Figures

a

b

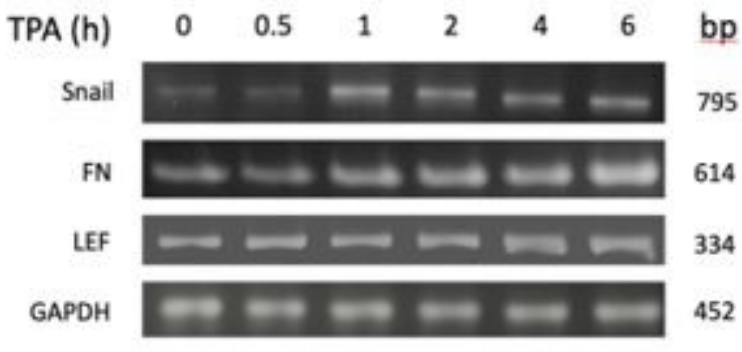

c

HepG2

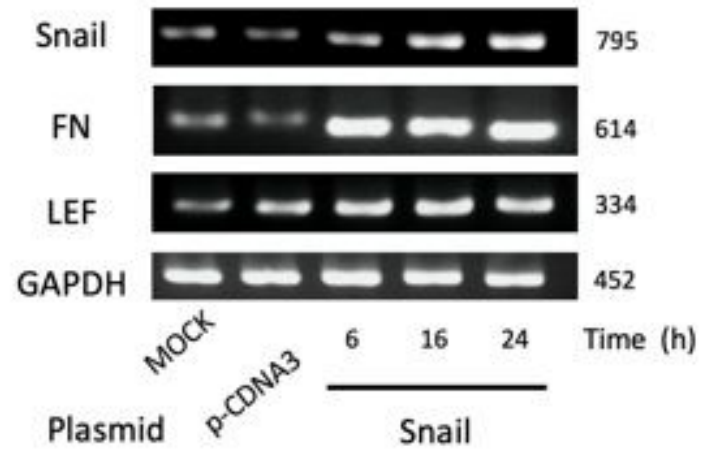

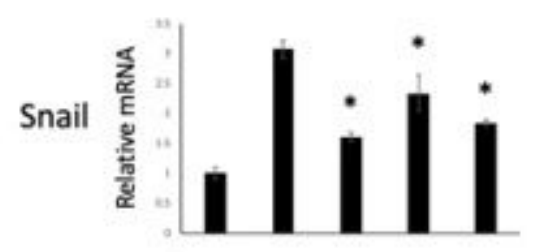
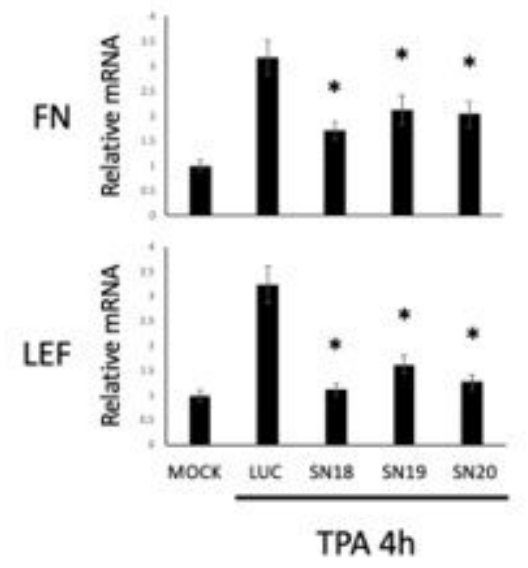

d

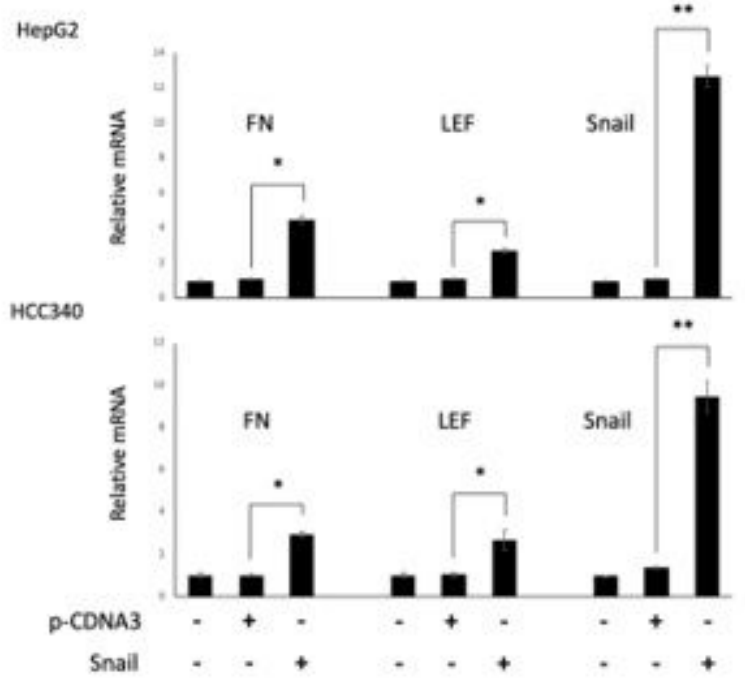

Figure 1

Treatment of TPA and overexpression of SNA elevated mRNA level of FN and LEF 
a

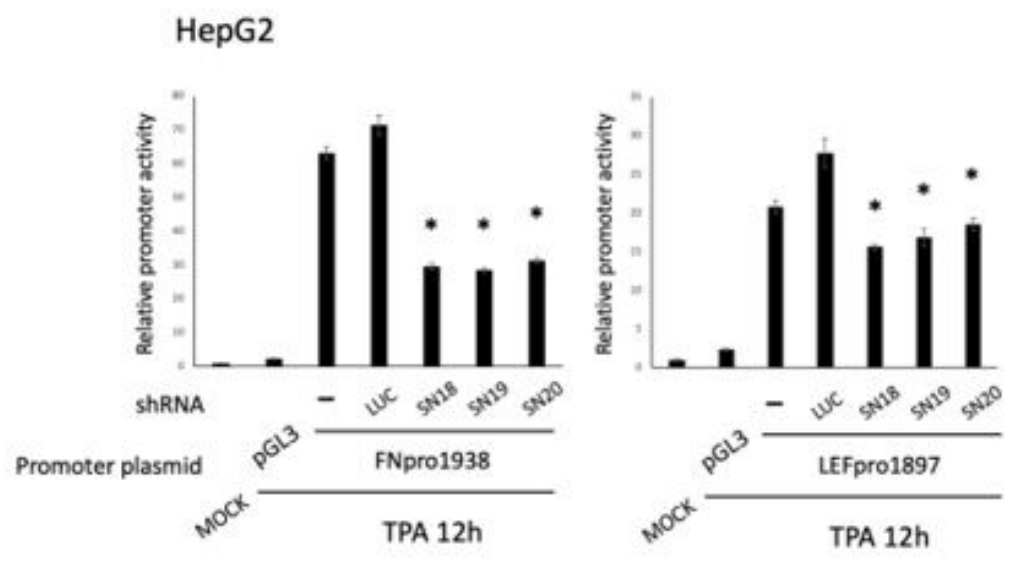

b

HCC340
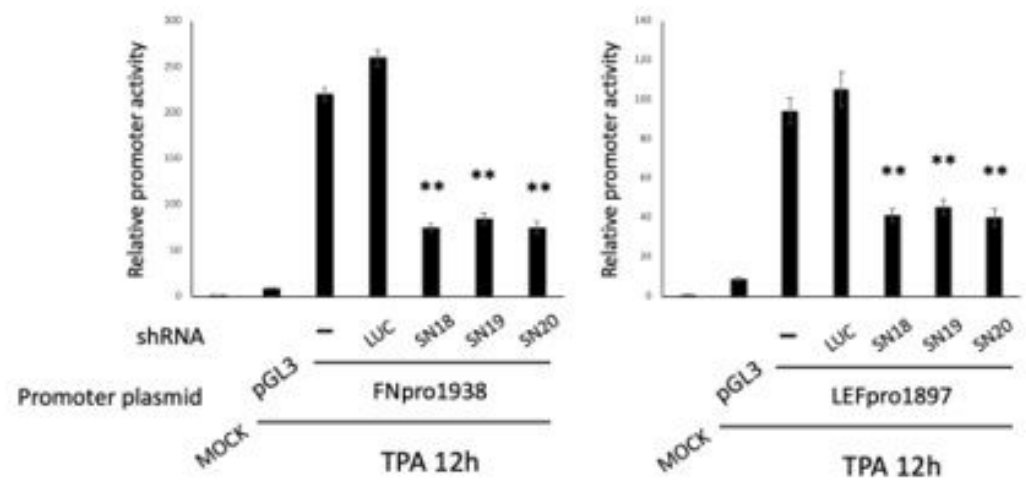

c

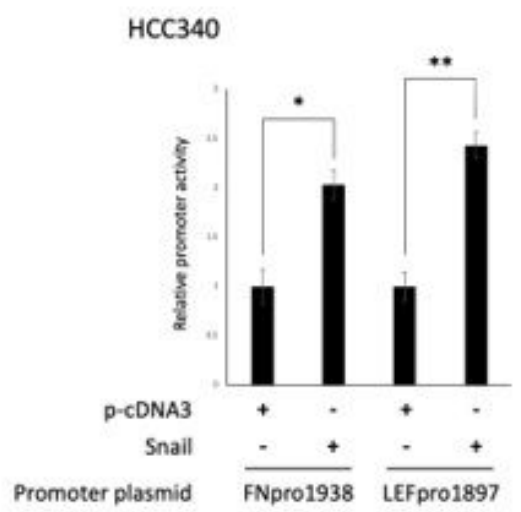

Figure 2

SNA is essential for constitutive and TPA-induced promoter activation of FN and LEF 
a

HepG2

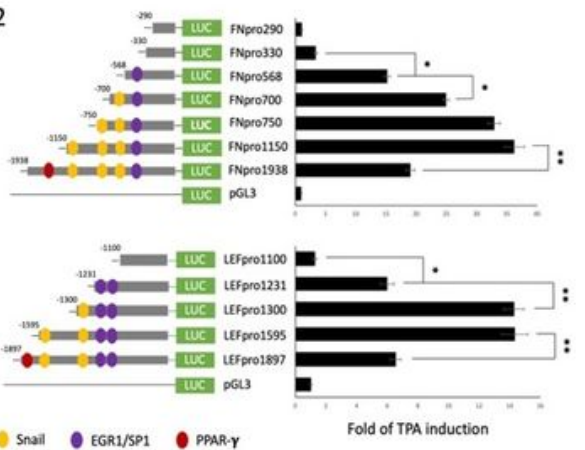

HCC340

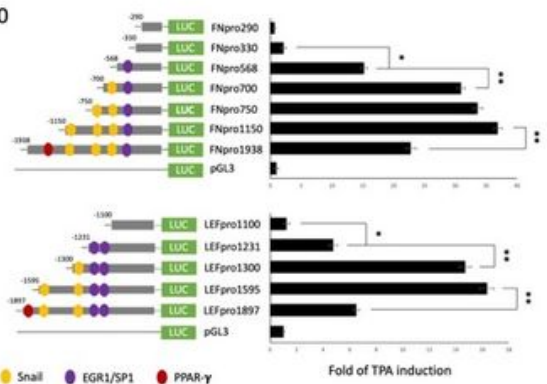

HepG2

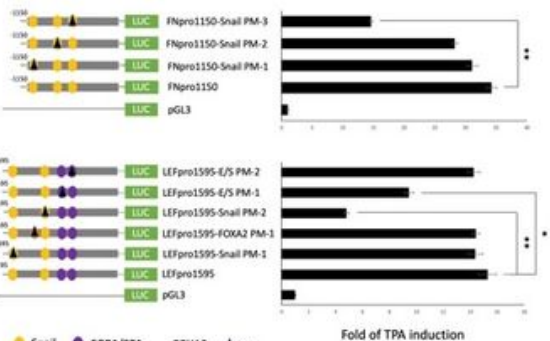

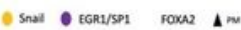

d

HCC 340

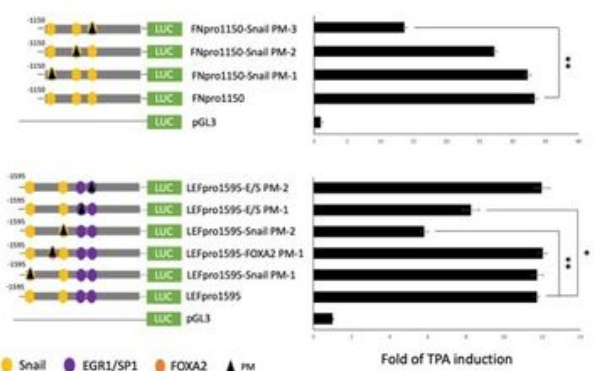

Snail EGR1/SP1 P FOXA2 A

Fold of TPA induction

\section{Figure 3}

Deletion mapping and site directed mutagenesis for identifying TPA-responsive element on fibronectin and LEF promoter 

HepG2
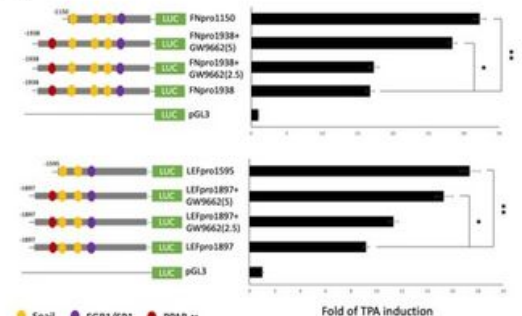

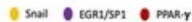

b

HCC340

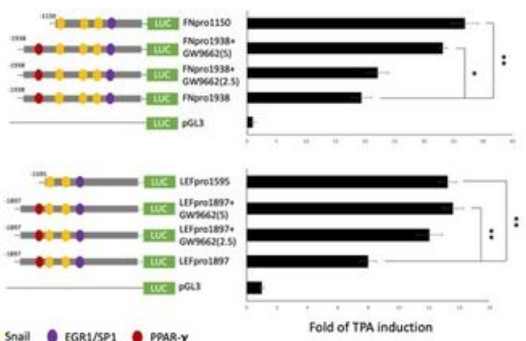

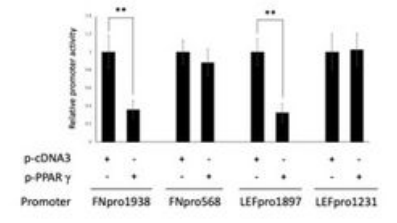

f

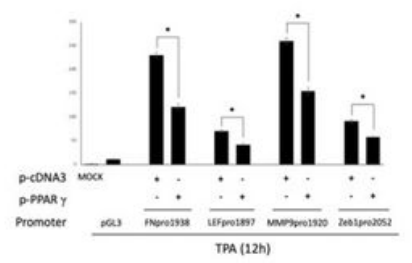

e

HepG2

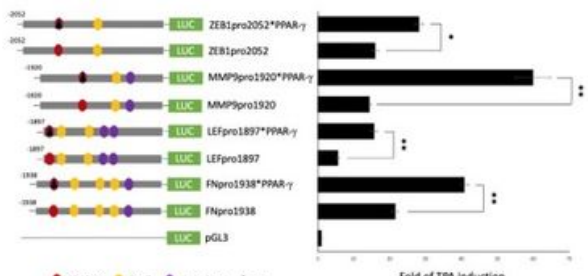

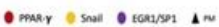

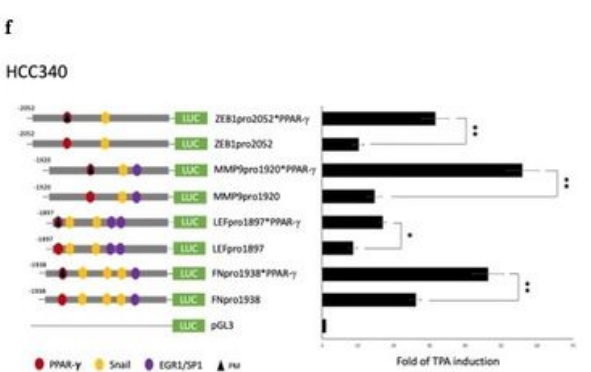

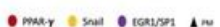

\section{Figure 4}

PPAR-y is responsible for negative feedback against the SNA-upregulated transcription for FN and LEF 


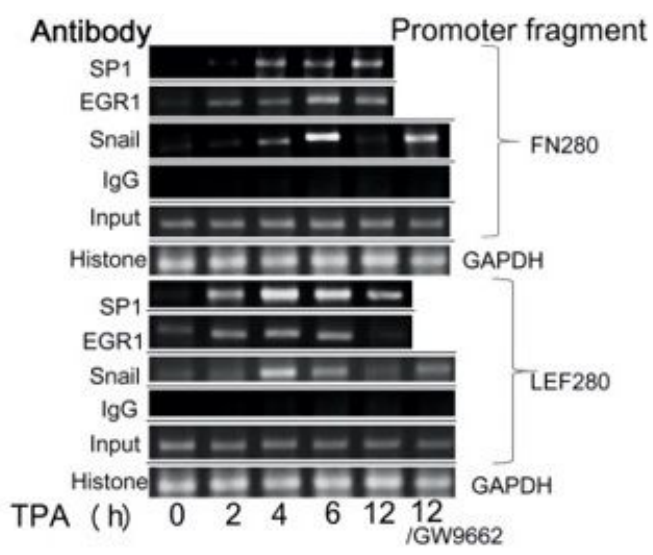

b

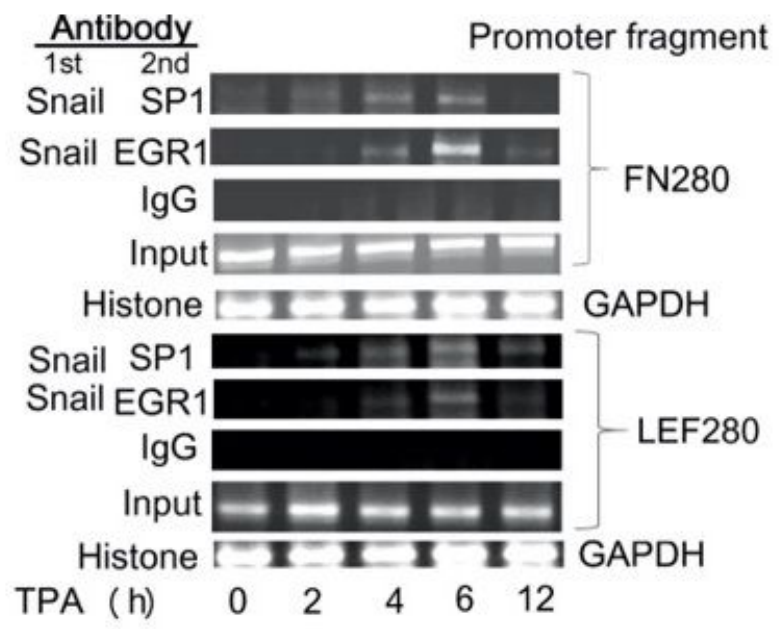

c
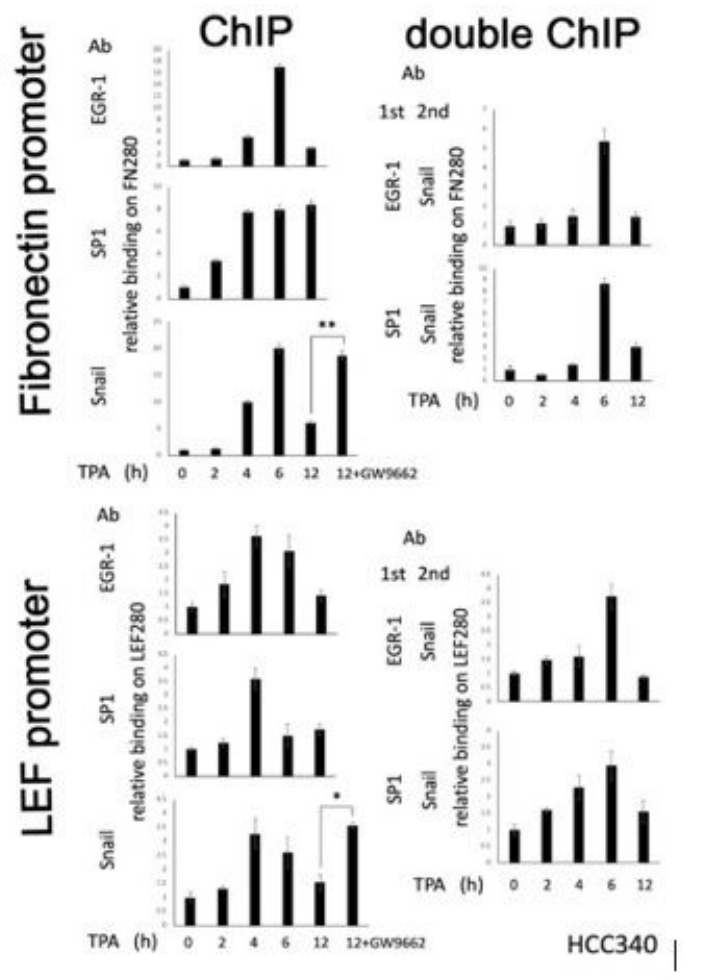

d

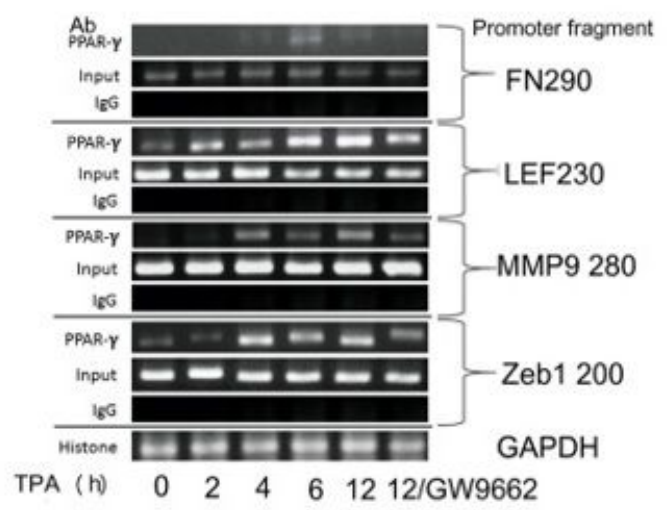

Figure 5

ChIP and double ChIP assay for TPA induced binding of transcription factors on promoter of FN and LEF 


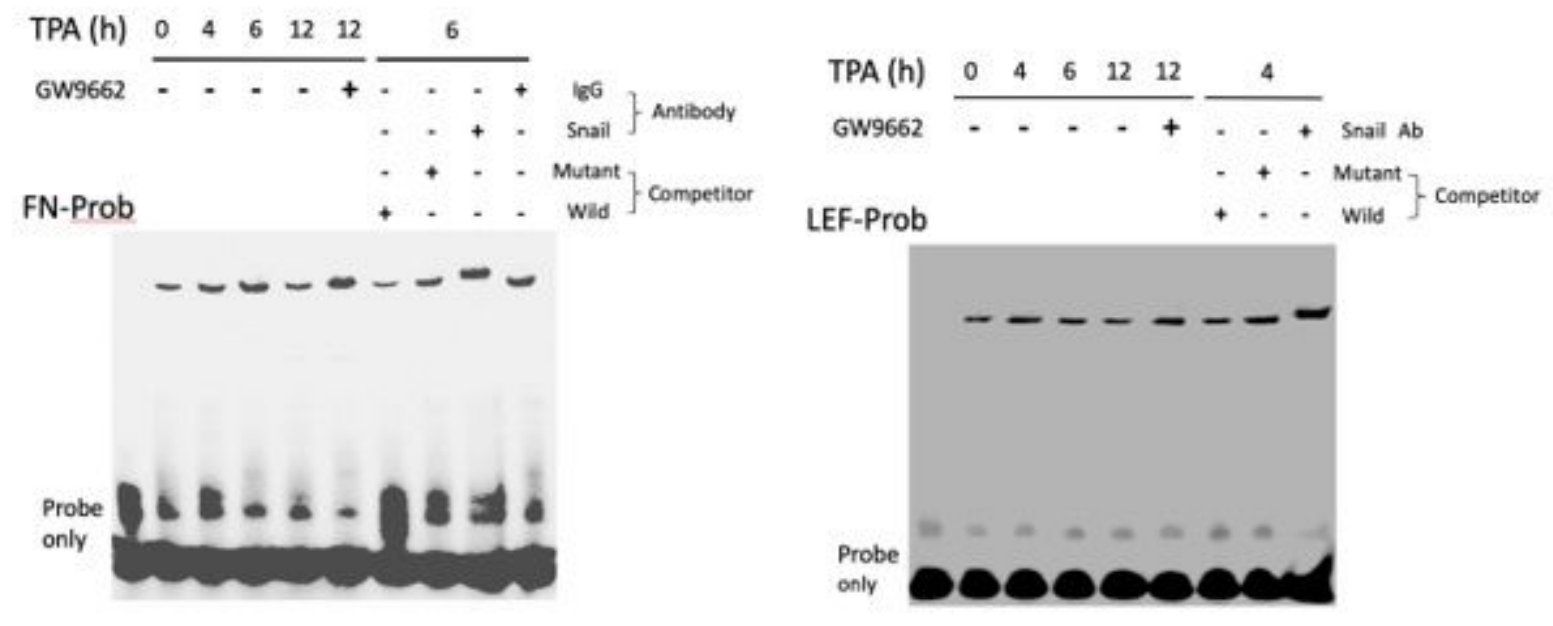

Figure 6

EMSA for TPA induced binding of SNA on putative regions of FN and LEF promoter 
a
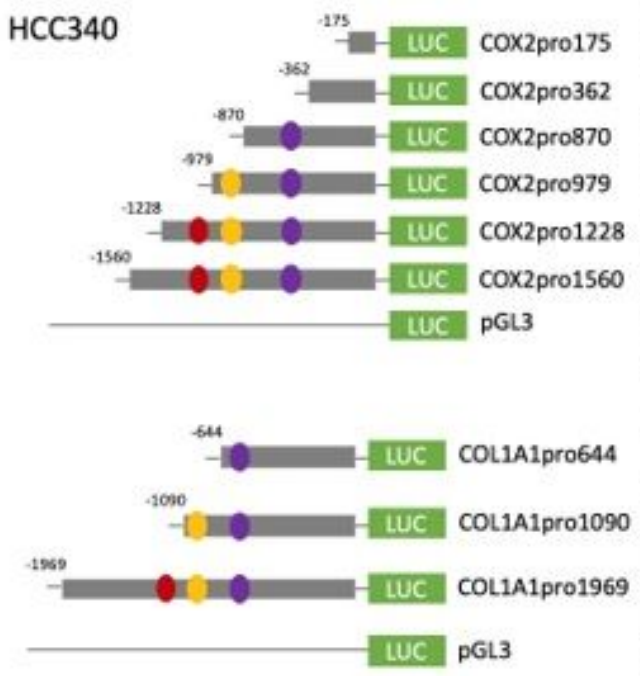

PPAR-y Snail e ER1/SP1

b
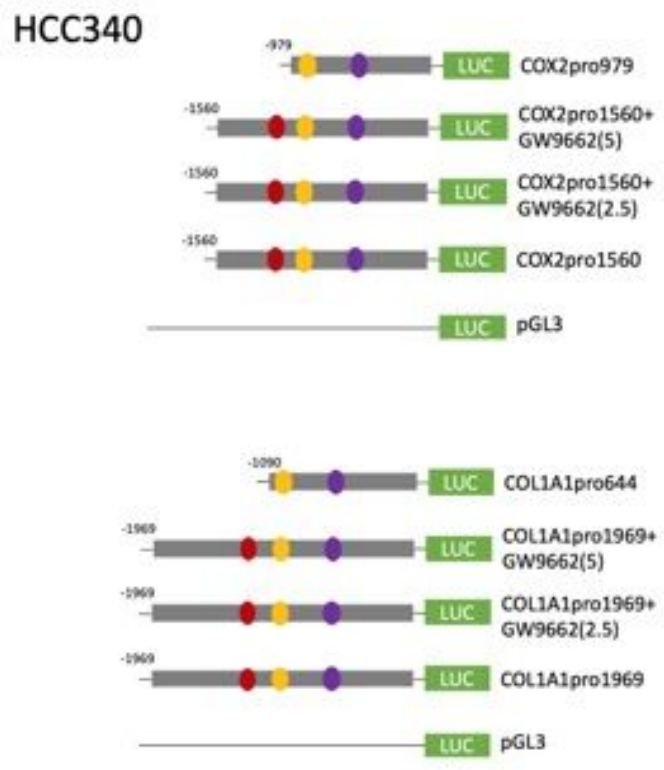

PPAR- $\gamma$ Snail EGR1/SP1
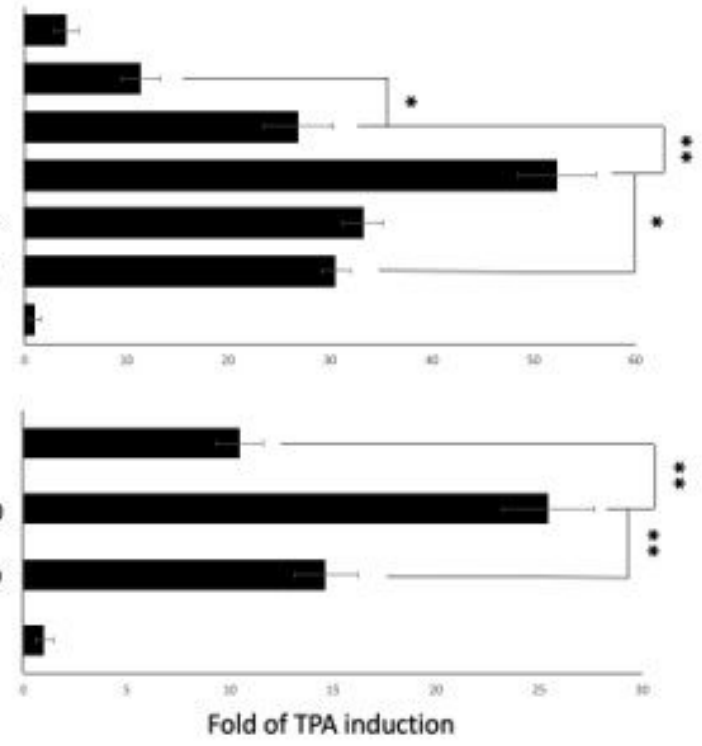

Fold of TPA induction

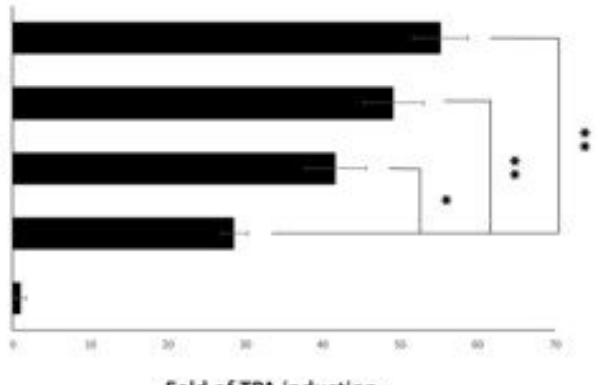

Fold of TPA induction

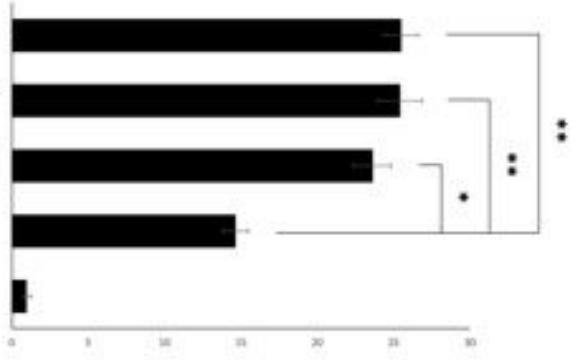

Fold of TPA induction

\section{Figure 7}

SNA-upregulated promoter activation COX 2 and COL1A1 is negatively feed backed by PPAR-y

\section{Supplementary Files}

This is a list of supplementary files associated with this preprint. Click to download. 
- Supplemental0103.docx

Page 28/28 